
\title{
28 Research Suare \\ Linking Tree Cover Change to Historical Management Practices in Urban Parks
}

Sabine Nix ( $\nabla$ nixs@sas.upenn.edu )

University of Pennsylvania https://orcid.org/0000-0001-5633-899X

Lara Roman

USDA Forest Service Northern Research Station

Marc Healy

Clark University

John Rogan

Clark University

Hamil Pearsall

Temple University

\section{Research Article}

Keywords: Urban ecology, Urban forestry, Urban parks, Change detection, Aerial images, Land cover change

Posted Date: December 30th, 2021

DOl: https://doi.org/10.21203/rs.3.rs-975849/v1

License: (c) (1) This work is licensed under a Creative Commons Attribution 4.0 International License. Read Full License 


\section{Abstract}

\section{Context}

Urban parks provide critical ecological, health, and social benefits, constituting a substantial proportion of urban tree canopy (UTC) within a given city. As cities set ambitious UTC targets, it is critical to understand the social drivers of UTC changes in parks.

\section{Objectives}

We sought to uncover the feedbacks between social processes, including historical events, and park UTC in a post-industrial city that experienced substantial population loss and urban park disinvestment.

\section{Methods}

Our mixed-methods approach involved quantifying spatiotemporal UTC changes and connecting those changes to historical management practices for three parks in Philadelphia, PA (US). We delineated UTC using aerial imagery between 1959 and 2018, and synthesized information from archival records and semi-structured interviews about historical management practices.

\section{Results}

We found substantial UTC gains between 1959 and 1980, due to both: (a) budget cuts, mowing cessation, and associated unintended forest emergence; and (b) purposeful tree planting and reforestation activities. While some UTC gains were purposeful, others were unintentional and reflect successional processes on unmaintained lands. Contrary to literature suggesting that financial investment would lead to UTC gain, we saw declining UTC following an influx of new funding post-2000 due to construction and ecological restoration.

\section{Conclusions}

We found differing pathways leading to convergent outcomes of UTC gains. Across the three parks, differing historical processes and management goals for park landscapes had important ramifications for UTC. Our work suggests that landscape management could benefit from an improved understanding of how historical processes impact land cover.

\section{Introduction}

Urban parks are a critical facet of sustainability in cities around the world. Parks encourage exercise, promote mental health, offer spaces for recreation, and provide substantial habitat heterogeneity and biodiversity (Maller et al. 2009; McCormack et al. 2010; Konijnendijk et al. 2013; Nielsen et al. 2014). Urban parks often include highly manicured areas in addition to natural areas, with all greenspace types offering substantial ecological and social benefits to human communities (Maller et al. 2009; Pregitzer et 
al. 2019). Many of the benefits of parks can be attributed to their relatively high concentration of trees, as compared to other urban land uses (Turner-Skoff and Cavender 2019).

Recognizing the importance of trees in cities, many cities in North America have established urban tree canopy (UTC) goals, often rooted in strategies to promote ecosystem services of trees as green infrastructure (Locke et al. 2017; Escobedo et al. 2019). Cities attempt to reach these UTC goals in various ways, such as yard tree giveaway programs, street tree planting, and planting in large parks (Oldfield et al. 2013; Nguyen et al. 2017; Doroski et al. 2018). Parkland is often the public land use with the most available space for additional UTC (O'Neil-Dunne 2012), making parks critically important to understanding past UTC change (Roman et al. 2021a) as well as meeting future UTC targets.

UTC within urban parks is subject to human and biophysical drivers, and the interactions among them (Roman et al. 2018). It is widely known that vegetative composition in urban parks changes depending on management practices over the course of many decades (Johnson and Handel 2015), but direct linkages and feedbacks between long-term UTC change and park management are understudied. Management actions that have the potential to affect UTC within parks include ecological restoration; the construction or abandonment of buildings, roads, and walkways; tree plantings; and tree removal due to pest or disease containment (Hostetler et al. 2013; Johnson and Handel 2015; Bonney and He 2019). For cities in forested biomes, the absence of management can lead to UTC increases. Forest emergence (Zipperer et al. 2002) can occur on abandoned lands after a disturbance event or human population decline (Lewis et al. 2017; Roman et al. 2018; Roman et al. 2021a). Furthermore, street trees often receive a significantly larger portion of municipal tree budgets than park trees (Hauer and Peterson 2016), suggesting that parks may not receive adequate funding relative to their substantial contributions to UTC.

Several recent studies have linked management practices to UTC change in developed urban lands (Bonney and He 2019; Roman et al. 2017, 2021a), but given that parks are critical components of urban UTC, a deep investigation of UTC changes specific to parks is warranted. More specifically, there is a need for interdisciplinary UTC change studies that integrate qualitative historical data with quantitative landscape patterns to highlight how UTC is impacted by the unique feedbacks between social and ecological processes occurring in parks due to their level of use by human communities and management to promote ecosystem services (Ogden et al. 2019; Roman et al. 2018, 2021a). To address this research need, we quantified and characterized spatiotemporal changes in UTC in urban parkland and connected those changes to historical management practices. Our mixed-methods approach enabled insights into both the rates and mechanisms of UTC change, and also illustrates the importance of integrating social science and landscape ecology approaches. We argue that historical processes are critical to the interpretation of land cover change, and that the abundance of archival materials in cities provides an opportunity to understand the mechanisms driving UTC spatiotemporal patterns.

\section{Methods}

\subsection{Study area}


We examined parks in Philadelphia, Pennsylvania (US). Philadelphia lies in the mesophytic forest region (Dyer 2006). As of 2010, the city had 1.5 million people (U.S. Census Bureau 2010), making it the fifthlargest city in the US. The city's tree canopy cover is $20 \%$ as of 2018 (O'Neil-Dunne 2019), and municipal sustainability leaders set a goal of reaching 30\% canopy cover across the city by 2025 (City of Philadelphia 2009). Municipal parks and recreation areas constitute $8 \%$ of the city's total land area but one-third of its UTC (O'Neil-Dunne 2011) and Philadelphia also has open spaces under federal, state, and private management (Roman et al. 2021a). In 2017, Philadelphia spent US\$52 per resident on its park system, ranking 78th out of the 100 most populous cities in the US (The Trust for Public Land 2017), following a trend of declining budgets and staffing for Philadelphia's parks since the 1970s (Brownlow 2006; Roman et al. 2021a). Philadelphia's park funding challenges are tied to the city's post-industrial transition, and also indicative of similar challenges in other cities that have experienced population loss and park disinvestment (Brownlow 2006; Joassart-Marcelli 2010; Roman et al. 2021a).

We focused on three parks: East and West Fairmount Park (referred to collectively as Fairmount Park) and the Schuylkill Center for Environmental Education (hereafter referred to as the Schuylkill Center, formerly the Schuylkill Valley Nature Center) (Fig. 1). These three parks were chosen because they are all located along the banks of the Schuylkill River and they have historical archival materials available. They also offered a way to compare parks with different histories and ownership as Fairmount Park is municipally managed, while the Schuylkill Center is privately managed.

Fairmount Park is the largest park in Philadelphia, covering 564 ha on the west side of the Schuylkill River and 267 ha on the east. Fairmount Park was created in the late 1800s by the Fairmount Park Commission (FPC), which acquired large estates along the Schuylkill River, with the intention of protecting the city's water supply, providing recreational opportunities, and preserving scenic landscapes (Armstrong 2012; Milroy 2016). The park hosted the 1876 Centennial International Exposition, which led to the construction of roads, fountains, and cultural institutions, in addition to extensive landscaping (Armstrong 2012). Currently, Fairmount Park contains a mix of lawns with planted trees, cultural institutions, and natural forested areas. The park was managed by the FPC before the Commission was absorbed into Philadelphia Parks and Recreation (PPR) following a 2008 ballot referendum. Notably, the FPC was chronically under-funded since its inception (Milroy 2012), and budget and staffing shortages became especially challenging in the late 20th century (Roman et al. 2021a). For the purposes of this study, we excluded the portion of West Fairmount Park south of West Girard Avenue (32 ha) because it is managed by the Philadelphia Zoo.

The Schuylkill Center covers 138 ha in the Andorra neighborhood of northwest Philadelphia, and has been privately owned and managed as a non-profit since its creation in 1965. Today, it is the largest privately managed open space in Philadelphia. Prior to serving as a nature center, the land was primarily used for agriculture and timber. Since the creation of the nature center, it has been transformed through both intentional restoration as well as forest emergence (Nase and Kirkpatrick 2017). Today, the center is largely a forested natural area along with smaller areas of meadows, ponds, and wetlands.

\subsection{Tree Cover Change}


Our mixed-methods study followed the approach established in Roman et al. (2021a) and involved: 1) quantifying spatiotemporal changes of historical UTC using aerial imagery; and 2) qualitatively connecting UTC changes to management actions by gleaning insights from park reports, newspaper articles, and semi-structured interviews with park professionals.

2.2.1 Aerial Imagery. To assess canopy change, we manually delineated UTC over historical aerial imagery. UTC over entire cities is often estimated using the random point method (Nowak and Greenfield 2012; Ucar et al. 2016; Kaspar et al. 2017; Hilbert et al. 2019; Roman et al. 2021a), which is usually summarized at the citywide scale and does not enable spatially explicit analyses. Rapidly advancing remote sensing technology has made LiDAR and automated classification methods increasingly popular for spatially explicit assessments of intracity UTC patterns (O'Neil-Dunne et al. 2013). However, historical aerial photography remains one of the longest available forms of landscape data (Morgan et al. 2010), offering a temporal depth that is unavailable from LiDAR. We assessed change over 59 years in approximately 20-year increments using aerial photography captured in 1959, 1980, 2000, and 2018 (Table 1).

Table 1

Aerial imagery used in this study. Images were retrieved from the Pennsylvania Spatial Data Access (PASDA) and the Delaware Valley Regional Planning Commission (DVRPC)

\begin{tabular}{|lllll|}
\hline Year & Color & Imagery Provider & Resolution $(\mathbf{m})$ & Leaf Status \\
\hline 2018 & Color & City of Philadelphia & 0.076 & Off \\
\hline 2000 & Grayscale & DVRPC & 0.46 & Partial \\
\hline 1980 & Grayscale & DVRPC & 0.61 & Partial \\
1959 & Grayscale & DVRPC & 0.61 & Off \\
\hline
\end{tabular}

2.2.2 Image Preprocessing. The 2018 and 2000 aerial photographs were orthorectified to the Pennsylvania State Plane coordinate system. The 1959 and 1980 imagery was first cropped to minimize edge distortion and then georeferenced to the orthorectified 2018 imagery in ArcGIS 10.6 (Environmental Systems Research Institute 2018). Additional information on georeferencing methods is included in Online Resource 1 (Supplementary Information S1).

2.2.3 Polygon Delineation and Change Detection: Polygons representing canopy cover were drawn according to a defined series of rules (Table 2), adapted from Zhou et al. (2011). We defined a minimum mapping unit of $100 \mathrm{~m}^{2}$, which allowed us to maintain consistency across all years based on the smallest patches that the interpreters could definitively classify as tree cover in the 1959 and 1980 imagery (the years with the lowest spatial resolution). Because there is no definitive method of 
distinguishing trees and shrubs in two-dimensional images (Kaspar et al. 2017), both tree and shrub cover were included in our analysis (Nowak and Greenfield 2012). Additional information on polygon delineation is included in Online Resource 1 (Supplementary Information S2).

Table 2

Rules for delineation of canopy cover patches

\section{A canopy cover patch must be greater than $10 \mathrm{~m}$ in width, and greater than or equal to $100 \mathrm{~m}^{2}$}

2. Exclude a gap/opening within a forest patch if it is at least $10 \mathrm{~m}$ by $10 \mathrm{~m}$ wide at the widest section of the gap

3. Visually distinct trees should be included as individual canopy cover patches if they are at least $10 \mathrm{~m}$ wide and $100 \mathrm{~m}^{2}$

4. Separate roads from canopy cover patches only if the width not covered by tree canopy is greater than $10 \mathrm{~m}$ wide

5. Edges of patches that extend beyond park boundary should be clipped to park boundary after all polygons are delineated

To characterize the spatial patterns of canopy cover over time, we calculated four metrics: (1) total tree cover; (2) total number of patches; (3) mean patch size; and (4) largest patch size. To visualize UTC changes, subsequent years were overlaid to determine areas where canopy has been lost, gained, or persisted.

For purposes of this study, persistent UTC refers to tree cover that was delineated in the same location between two subsequent images (1959-1980, 1980-2000, and 2000-2018). We calculated persistent UTC and reported (a) the percent of persistent UTC relative to total UTC in the earliest image of each set of images compared, and (b) persistent UTC relative to total park area. In contrast with persistence, we defined stable UTC to be the percent of the UTC in 1959 that was present in each of the subsequent images (Roman et al. 2021a).

\subsection{Assessment of error}

While manual interpretation is considered a reliable method for tree cover detection (Morgan and Gergel 2013; Hilbert et al. 2019), it is important to minimize potential sources of error such as shadows, misregistration, and parallax (Richardson and Moskal 2014). To reduce error associated with shadows, all imagery used for this study was taken while trees were in the leaf off or partial leaf off stage, and in areas where edges of tree canopy were obscured, the edges were copied from one image's polygons to the other to minimize false change. Parallax errors and mis-registration between historical images could lead to areas of false change (Ucar et al. 2016). To minimize this challenge, a minimum mapping unit was used during delineation (Zhou et al. 2011), as previously described. 
Another potential source of error in manual delineation of land cover polygons comes from inconsistencies between interpreters (Congalton and Mead 1983; Morgan and Gergel 2013). One interpreter delineated all UTC patches to maintain consistency (Berland 2012), and a second interpreter delineated a subsection of the study area to assess agreement (Congalton and Mead 1983; Ucar et al. 2016; Roman et al. 2017, 2021a). The second interpreter re-delineated canopy cover for roughly $10 \%$ of the total area of each park within randomly placed 3 ha circular plots. Percent agreement (Supplementary Information S3) ranged from 87.4-96.2\%, depending on the specific park and year. Overall differences in interpreters' UTC estimates ranged from 0.8 percentage points to 5.6 percentage points (Table S3.1).

To determine whether UTC change between years could be considered detectable, we calculated the detectable change threshold following Roman et al. (2021a) (Supplementary Information S3). The detectable change thresholds varied between parks and between years. The detectable change thresholds for the entire 59-year period were 6.1, 2.1 and 4.7 percentage points for East Fairmount Park, West Fairmount Park and the Schuylkill Center, respectively (Table S3.2).

\subsection{Park Management}

To identify drivers of UTC change, we assessed archival park records and newspapers, and conducted three semi-structured interviews with park professionals. We created a timeline of major management events from archival reports and drew on the interviews to better understand the connections between historical events to UTC changes.

2.4.1 Archival Reports and Newspapers: FPC Annual Reports were reviewed to identify potential drivers of UTC change, such as tree removals, planting projects, severe storms, budget cuts, construction activities, and descriptions of mowing schedules. Wherever possible, we noted precise spatial information about these phenomena. We reviewed available annual reports from 1950 through 1988; the start date was selected due to the potential impacts of Interstate 76 (I-76, also known as the Schuylkill Expressway) construction, while the end date represents the last FPC annual report.

For the Schuylkill Center, historical management activities were summarized in a 2017 staff report detailing major planting plans and restoration strategies. As with the FPC Annual Reports, the document was reviewed for mentions of potential UTC change drivers.

In addition to park management records, we searched local newspapers such as the Philadelphia Inquirer and Philadelphia Daily News (from newspapers.com, Ancestry 2020) for references to major management actions and events related to UTC. We searched between 1950 and 2018 using the following search terms: Fairmount Park, Schuylkill Center, Schuylkill Valley Nature Center, overgrown, Schuylkill Expressway, restoration plan, mowing, tree removal, and tree planting.

2.4.2 Semi-structured Interviews: To fill in gaps in the archival records and build a more thorough understanding of UTC changes over time, semi-structured interviews were conducted with stewardship and land management professionals from both PPR and the Schuylkill Center. Utilizing these professionals' knowledge of their parks enabled us to link the changes we observed in aerial imagery to 
specific events and processes. Maps illustrating canopy gains and losses were shown to park professionals during each interview, with questions guiding the conversation toward recent or historical management decisions or restoration strategies that could have influenced UTC change across each 20year period. An interview with one Schuylkill Center staff member was conducted in November 2019 and interviews with two PPR staff were conducted in February 2021; these personnel were directly responsible for overseeing land management and also had personal experiences of working in the selected park spaces for 5-30 years.

\section{Results}

\subsection{Tree Cover Change}

UTC in West Fairmount Park and the Schuylkill Center increased between 1959 and 2018, with the largest increase observed between 1959 and 1980. East and West Fairmount Park experienced very different patterns of UTC change during the study period. In West Fairmount Park, UTC increased by 17.5 percentage points overall, well above the detectable change threshold, despite no detectable change occurring between 2000 and 2018. In East Fairmount Park, UTC change was not considered detectable based on the detectable change threshold for this park. The Schuylkill Center saw the largest gain in UTC, adding 34.4 percentage points (above the detectable change threshold). All three parks saw the smallest increases, or in the case of East Fairmount Park, the largest decrease, between 2000 and 2018 (Figures 34; Table 3).

Table 3

Summary of tree cover metrics for West Fairmount Park (WF), East Fairmount Park (EF), and Schuylkill Center (S)

\begin{tabular}{|rlllllllllllll|}
\hline Year & \multicolumn{2}{l}{ Tree Cover (ha) } & \multicolumn{4}{c}{ Tree Cover (\%) } & \multicolumn{3}{c}{$\begin{array}{l}\text { Number of } \\
\text { Patches }\end{array}$} & \multicolumn{4}{c|}{$\begin{array}{l}\text { Mean Patch Size } \\
\text { (ha) }\end{array}$} \\
\hline & WF & EF & S & WF & EF & S & WF & EF & S & WF & EF & S \\
\hline 1959 & 210.9 & 96.1 & 73.1 & 39.7 & 36.0 & 52.9 & 686 & 323 & 46 & 0.3 & 0.3 & 1.6 \\
\hline 1980 & 281.8 & 110.0 & 103.1 & 53.0 & 41.2 & 74.7 & 489 & 295 & 50 & 0.6 & 0.4 & 2.0 \\
\hline 2000 & 300.1 & 106.1 & 116.9 & 56.4 & 39.7 & 84.7 & 679 & 323 & 67 & 0.4 & 0.3 & 1.8 \\
\hline 2018 & 304.3 & 103.6 & 120.5 & 57.2 & 38.8 & 87.3 & 726 & 470 & 56 & 0.4 & 0.2 & 2.2 \\
\hline
\end{tabular}

In each park, a large portion of the UTC was persistent. In the Schuylkill Center, the amount of UTC that persisted between each set of images ranged from 92.5-94.5\% (Table 4), while in West Fairmount Park and East Fairmount park, the amount of UTC that persisted year to year remained around $83 \%$ and $73 \%$, 
respectively (Table 4). While the persistent UTC relative to tree cover remained consistent through time for each park, the amount of persistent UTC relative to overall park area increased throughout time for each park (Fig. 3, Table 4). Stable UTC (the amount of 1959 UTC that persisted between each set of images), was $68.3 \%$ for West Fairmount Park, $49.2 \%$ for East Fairmount Park and $86.7 \%$ for the Schuylkill Center.

Table 4

Persistent UTC for West Fairmount Park (WF), East Fairmount Park (EF), and Schuylkill Center (S)

\begin{tabular}{|lllllll|}
\hline Year & \multicolumn{4}{l}{ Persistent UTC (\%) Relative to Park Area } & \multicolumn{4}{l|}{ Persistent UTC (\%) Relative to Tree Cover } \\
\hline & WF & EF & S & WF & EF & S \\
\hline $1959-1980$ & 33.1 & 26.2 & 49.0 & 83.4 & 72.8 & 92.5 \\
\hline $1980-2000$ & 43.9 & 30.3 & 70.6 & 83.0 & 73.4 & 94.5 \\
\hline $2000-2018$ & 47.1 & 29.4 & 78.7 & 83.4 & 73.8 & 92.9 \\
\hline
\end{tabular}

The number of patches and mean patch size varied from year to year in East and West Fairmount Park, while the mean patch size increased over time in the Schuylkill Center. Between 1959 and 1980, when all three parks experienced the largest UTC gains, the number of patches decreased in East and West Fairmount Park, and increased by only four in the Schuylkill Center. The largest increases in mean patch size for all three parks were observed at the same time (Table 3). The size distribution of UTC patches shows a slight increase in small patches (100-200 $\mathrm{m}^{2}$ ) in East and West Fairmount Park (Fig. 2). In 1959, over $50 \%$ of the Schuylkill Center's patches were greater than $800 \mathrm{~m}^{2}$, which dropped to fewer than $20 \%$ greater than this size by 2018 (Fig. 2).

While each park saw an increase in the number of small patches, the size of the largest patch grew each year, with the most marked increase occurring between 1959 and 1980 for all parks. Between 1959 and 1980 , the percent park area covered by the largest patch increased from $6.2-20.2 \%$ in West Fairmount Park, and from 10.6-20.2\% in East Fairmount Park. The Schuylkill Center's largest patch covered 47.9\% of the park in 1959, which had increased to $85.5 \%$ by 2018 .

\subsection{Park Management}

Below, we outline relevant management decisions and other UTC change drivers that occurred from the 1950s through 2010s. We have organized these historical findings around several major drivers in a broadly chronological narrative. For Fairmount Park, major drivers include highway construction, budget cuts, external funding, and ecological restoration, while for the Schuylkill Center, major drivers include intentional reforestation, ecological restoration, and the creation of meadow and pond habitats.

\subsubsection{Fairmount Park}




\section{Construction of I-76}

There was an increase in tree cover of 13.3 percentage points between 1959 and 1980 in West Fairmount Park, following the construction of I-76 in 1959, likely due to forest infill near the highway after the construction ended. Understanding the history of I-76's construction suggests that many of the UTC gains identified along I-76 between 1959 and 1980 could have resulted from plantings to compensate for the loss of trees during construction (Fig. 5 d).

Controversy surrounding the proposed route through West Fairmount Park caused construction delays (The Philadelphia Inquirer 1959). While the park commissioners approved the plan for I-76 to cross the park, they opposed the proposed route that would disturb views to the river (FPC 1952; The Philadelphia Inquirer 1953a). In addition to the commissioners' concerns, several city residents and taxpayers filed a lawsuit, stating that the FPC had no right to allow interstate construction within the park (The Philadelphia Inquirer 1953b). Despite these objections, the highway was completed through West Fairmount Park in 1959.

The construction of $1-76$ required clearing many surrounding trees; 1000 trees were documented to have been removed, and many other removals were likely unrecorded (FPC 1952; Maxwell Smith 1953). While this means UTC loss prior to 1959, the FPC had begun replanting by 1958 (FPC 1958) and was planning to spend US\$1,000,000 on landscaping in affected areas (Rosen 1958). In addition to plantings funded by the FPC, the Pennsylvania Highway Department funded a landscaping contract that involved removing standing dead or otherwise undesirable trees along the expressway and planting 1,607 deciduous and flowering trees along the western banks of the Schuylkill River beginning in 1960 (FPC 1959).

\section{Budget cuts}

Changes to park budgets in the 1970s-80s had long-term impacts on UTC within Fairmount Park. The FPC faced a series of budget cuts in the 1970s that led to a reduction of one-third of the total park staff in the city in less than ten years, and a loss of half of the park maintenance staff in three years. These personnel and resource constraints severely restricted the park managers' ability to maintain trees and sustain a consistent mowing schedule (FPC 1974-1975), likely prompting unintentional land cover change.

By the early 1970s, the budget constraints and job freezes forced the FPC to defer their emergency tree removal program (FPC 1971-1972) during a time when dead trees were reported to be the "biggest problem in the Park," largely tied to the devastating impacts of Dutch elm disease (Ophiostoma sp.), canker stain (Ceratocystis platani) (FPC 1969-1970), and two storms (in August-September 1971 and June 1972) that caused an estimated US\$1,500,000 in park damage (FPC 1971-1972).

On top of the difficulties posed by dead and dying trees, the FPC reported that "the number one task of the [maintenance] division. .. continues to be the care and maintenance of ... lawn" (FPC 1971-1972). To reduce spending during this period of budget reductions, the FPC assigned maintenance priority to 
different areas of the parks based on their use and exposure (FPC 1973-1974). High priority areas, such as East and West River Drive (now known as Kelly Drive and MLK Drive, respectively), were placed on twoto-four-week mowing schedules, while lower priority areas "received attention as required or were left untouched in their natural state" (FPC 1976-1977).

In the 1980s, overgrown vegetation became apparent in many Philadelphia parks, including East and West Fairmount Park, occasionally leading to tension with the public. For example, the weeds and bushes along West River Drive, a high priority area, were so overgrown that they obstructed the view to Boathouse Row, a historic Philadelphia site on the eastern bank of the Schuylkill River (Penman 1987). Walking and biking trails in Fairmount Park were in poor condition and surrounded by overgrown vegetation that "turned sections of the path into a virtual jungle" by the late 1980s (Washington 1987). According to the park's director at the time, the paths were only cut and cleaned once a year due to lack of resources (Washington 1987). In 1981, Philadelphia's mayor responded to overgrown grass by asking to increase the mowing schedule to twice a month rather than every six weeks, as had been the practice decades prior (Leary 1981).

According to current park staff, the budget cuts and subsequent decrease in mowing led to UTC gains in areas that included Montgomery Drive, Belmont Plateau, North George's Hill (Fig. 5c), Lemon Hill, Greenland Nursery (Fig. 5b), and a large region to the east of Chamounix field (Fig. 5a). Some of these areas were mowed only every six months to a year and correspond to areas with UTC gains recorded between 1959 and 1980 (Figures 5a-5c).

\section{External funding and restoration}

Despite a shrinking budget and limited staff, the FPC continued to conduct restoration activities throughout East and West Fairmount Park in the late 20th century. Some of these efforts included removing hundreds of dead trees from along East and West River Drives and Belmont Avenue (FPC 19731974; FPC 1974-1975), clearing the paths in Lansdowne Glen (FPC 1986-1987), and landscaping around the Horticulture Center, Memorial Hall and the Philadelphia Museum of Art (FPC 1971-1972). In addition to projects led and funded by the FPC, external grants and organizations offered opportunities for additional special programs that had ramifications for UTC.

One particularly notable program was the 10,000 Trees program, led by the Pennsylvania Horticultural Society (PHS), a non-profit which today administers many urban greening programs (Rosan and Pearsall 2017; Roman et al. 2021a). Under the leadership of PHS Executive Director Ernesta Ballard, the 10,000 Trees program planted trees throughout Philadelphia parks in the 1970s (PHS 1973). Other external grants included a Pew Charitable Trusts grant to the John Bartram Association, which funded the restoration of East River Drive (FPC 1986-1987; FPC 1987-1988) and a grant from the Albert M. Greenfield Foundation that funded the beautification of high visibility sections of the park, such as Belmont Plateau and East River Drive, that had insufficient maintenance (Collmore 1990; Corr 1990). 
In 1996, the FPC received a US\$14.3 million grant from the William Penn Foundation. This grant established the Natural Lands Restoration and Environmental Education Program (NLREEP) to survey and restore natural areas in the FPC's large watershed parks (FPC 1997-1998; Goldenberg and Horwitz 2000). In many areas that were previously lawns, FPC staff stopped mowing in order to create roughly 34 ha of meadows across the park system, including in East and West Fairmount Park (Ung 2000). While the FPC had previously faced difficulties maintaining lawns with their limited budget, park officials noted that "the shift was purely for ecological reasons, not to save money" (Ung 2000). The park placed signage in some of the newly created meadow habitat, including near the Chamounix tennis courts and near the Horticulture Center, to create an educational opportunity for parkgoers.

In addition to large grants from foundations, many areas of Fairmount Park were restored with funds raised by individuals or small organizations. For example, East Fairmount Park's Fairmount Water Works, which was built in the early 1800s as the country's first municipal water system, was neglected after it ceased operations in 1911, leading to disrepair and overgrown vegetation across the 5 ha site (Dribben 2006). The Junior League of Philadelphia began fundraising for the site in 1974, but in the 1990s and early 2000s, Ernesta Ballard "almost single-handedly raised \$20 million for the project" (Dribben 2006). By 2007, many of the areas that were previously overgrown had been cleared, and new Tilia sp., Platanus x hispanica and Liquidambar styraciflua trees had been planted (Smith 2007).

Another area of focus for the FPC were the Cherry Blossom (Prunus sp.) groves throughout Fairmount Park. The FPC planted Japanese cherry trees (Prunus sp.) donated by the Japanese government and the Women's Washington Bicentennial Committee along East River Drive in 1991 and 1992 (FPC 1991-1992). In 1998, The Japan America Society of Greater Philadelphia announced a donation of 1,000 trees to Fairmount Park (FPC 1997-1998; Fish 1998), including some planted near Memorial Hall (Fish 1998). Around the year 2000, more trees were planted near the Japanese House (FPC 1997-1998; Fish 1998) and along West River Drive (The Philadelphia Inquirer 2000).

\section{Reinvigorating the park through restoration, planting and maintenance}

While UTC in West Fairmount Park tended to increase throughout our study period, the change in UTC between 2000 and 2018 was not considered detectable in either West or East Fairmount Park. The lack of UTC gains in this time period aligned with a renewed emphasis on restoration and construction in the parks.

Beginning in the 2000s, the park began to take on more large-scale ecological restoration efforts throughout East and West Fairmount Park, generally involving invasive species removal, planting native forest species, and meadow creation (PPR 2013). According to park staff, three large areas of forest restoration during this time period occurred to the north and south of the Horticulture Center in West Fairmount Park (Fig. 6b) and near Greenland Nursery (Fig. 6a). These areas were planted with trees and shrubs, with deer fences installed to protect new plantings. These areas align with some of the largest areas of UTC loss detected during this time period, likely due to the removal of invasive species and clearing in preparation for new planting (Figures $6 \mathrm{a}$ and $6 \mathrm{~b}$ ). While forest restoration activities are 
expected to produce long-term UTC gains, especially with gains in native flora (PPR 2013), invasive tree removal can produce temporary UTC loss.

In addition to the restoration work, some construction projects and building reopenings occurred in the early 2000s, including reopening Memorial Hall as the Please Touch Museum (a children's museum) and an expansion of the parking lot (Fig. 6c), and constructing the School of the Future (Fig. 6d), both of which are visible as tree cover loss between 2000 and 2018.

Notably, mowing frequency began increasing in the 1990s and 2000s, reversing the earlier trend towards infrequent mowing. Since the late 1990s, the FPC outsourced mowing with the frequency increasing to one to two week cycles. For instance, in fiscal year 1997, the FPC reported mowing $88 \%$ more grass compared to prior years (FPC 1997-1998).

\subsubsection{The Schuylkill Center}

\section{Reforestation and creation of a nature center}

Between 1959 and 2018, the Schuylkill Center's UTC increased by more than 30 percentage points, with most gains occurring between 1959 and 1980, coinciding with the creation of the Schuylkill Center. Prior to the founding of the Schuylkill Center in 1965, the land was used for agriculture for more than four centuries. The sections of the Schuylkill Center that were used for agriculture are largely flat, and outlines of some fields are still visible today in topographical maps of the center. Some of the sections of the land that were unsuitable for farming, such as the two deep ravines on the property, were utilized for timber (Nase and Kirkpatrick 2017). Current staff indicate that these ravines now have some of the largest and oldest trees on the property.

Beginning in 1963, the land was managed with the intention of creating a nature center. By 1970, the center was celebrated for its abundant wildlife, including over 170 species of birds (Fowler 1970). The landscape became formally protected following a land donation for environmental education in 1965. The land was developed into an educational nature center with the help of a neighborhood businessman (Haas 1967).

By 1973, the reforestation of the Schuylkill Center was well underway, as six fields had grown into woodlots. One of the major restoration activities conducted in the 1980s was the reforestation of 2 ha in the northern corner of the property. This area was meant to create habitat for wildlife and educational opportunities for visitors. Management objectives at that time centered around environmental and educational aspects of restoration, in contrast to the 1976 planting of a Pinus sp. plantation on the property with the express intention of using the trees for timber (Fig. 7a). More recently, in 2015, over 200 trees and 100 shrubs were planted to create Jubilee Grove (Nase and Kirkpatrick 2017).

\section{Managing for ecosystem diversity and educational use}


In the midst of rapid reforestation and UTC gains, the staff decided in 1974 that it would be beneficial to maintain some portion of the land in open fields (Nase and Kirkpatrick 2017). Some of the areas maintained as meadows include Butterfly Meadow, which has been mowed since the 1970s, and Spring Lane Meadow, which was created in 2010 and expanded to 5.3 ha in 2012. Both meadows are monitored regularly for invasive species and mowed to provide habitat for birds and pollinators as well as educational opportunities for visitors (Nase and Kirkpatrick 2017).

In addition to meadow maintenance, land management at the Schuylkill Center included creating and restoring several wetlands and ponds. Cattail Pond was first created in 1966 to provide habitat for aquatic species and was subsequently restored through dredging and planting in 1991 and 2014 to enhance its value as an educational tool. Wetland areas were constructed along two small streams that flow into the Schuylkill River sometime after 1989, when they were first proposed. The goal of these wetlands was to create habitat, provide educational opportunities, and to increase biodiversity on the property. In 2002, with similar goals in mind, the Springhouse Pond was created with funding from a William Penn Foundation Grant (Nase and Kirkpatrick 2017).

More recently, the Schuylkill Center has also been the site of research projects aimed at developing techniques to control invasive species and reintroduce Castanea dentata that are considered more tolerant of Cryphonectria parasitica. Beginning in 2000, Penn's Native Acres was created to research techniques aimed at controlling invasive species, specifically Microstegium vimineum. The project encompassed 4 ha of forest, meadow and pond habitat in 2003. External funding from the Pennsylvania Urban \& Community Forestry Council, the National Fish and Wildlife Foundation, and ArcelorMittal have allowed the area to be continually restored. Invasive species were removed, deer fencing installed, and native plantings were conducted while several Liriodendron tulipifera were injected with herbicide to increase the amount of light that reached the understory. The American Chestnut Grove was planted with 50 Castanea dentata seedlings thought to be more tolerant to blight across 2 ha. Preparation for this project involved clearing space for the new plantings, which allowed invasive species to establish in the area while many of the chestnut trees succumbed to blight (Nase and Kirkpatrick 2017). In the 2000s, management also included daylighting sections of forest (Fig. 7b), which was followed by regrowth of invasive trees. In 2017, these areas were replanted with native trees.

\section{Discussion}

We observed divergent pathways leading to convergent outcomes-substantial long-term net UTC increase-in urban parks with distinct management histories. UTC increased due to both purposeful planting and reforestation activities as well as unintentional forest emergence. In West Fairmount Park, tree cover increases largely came from natural successional processes on unmaintained lands. In the context of post-industrial Philadelphia, budget and personnel cuts led to mowing reductions, which then enabled forest patches to emerge and expand. This finding aligns with literature from other postindustrial and shrinking cities (Haase et al. 2014; Lewis et al. 2017), particularly cities located in forested biomes, where forests grow readily on abandoned and unmaintained lands (Roman et al. 2018). Although 
such unintentional forest emergence increases UTC, and might therefore seem to support present-day canopy goals, undirected forest succession is not necessarily perceived as beneficial to park managers and the general public. Indeed, the "weedy" appearance of Philadelphia's public parks was depicted alongside unmaintained buildings and trails as a sign that the parks were a "neglected treasure" (Finkel 1986) in the late 20th century (Brownlow 2006). Yet even in the face of municipal disinvestment in parks, we documented planting initiatives in manicured lawn areas over many decades that yielded UTC increases through non-profit partnerships and foundation funding. This finding is indicative of broader national trends, as throughout the US, many municipal park departments have become increasingly reliant on funding from corporations, foundations, and grants (Walls 2014; Gabriel 2016; Nguyen et al. 2017). Meanwhile, the non-profit Schuylkill Center's transition from agriculture to forest is a common story in the northeastern and mid-Atlantic region of the US (Jeon et al. 2013). In this particular situation, the reforestation occurred as environmental advocates sought to preserve open space amidst late-20th century neighborhood development in Philadelphia's outer neighborhoods (Roman et al. 2021a). Longterm UTC increase was an implied (but not explicit) aspect of the Center's founding purpose to support wildlife habitat and provide nature education.

Our results reinforce previous findings that protected open spaces in cities have more persistent UTC than other urban spaces (Roman et al. 2021a). Despite differing management goals, UTC change and patch dynamics followed similar trajectories in each of the three parks studied. While UTC increased, the total number of patches did not follow any clear patterns. Instead, the proportion of small patches (100-200 $\mathrm{m}^{2}$ ) and the size of the largest patch increased over time in each park (Fig. 2). Rather than suggesting substantial growth of individual UTC patches, these results likely indicate that trees grew to connect smaller patches over time. We also found that the majority of UTC change visible in the parks occurred at the edges of larger patches, while the centers of larger patches tended to be highly persistent (Fig. 3). UTC growth occurred at the edges of patches as mowing cessation led to unintentional forest emergence and expansion, while restoration and maintenance activities tended to occur in areas that were more visible to parkgoers. Most construction leading to UTC loss also took place on the edges of larger patches. As canopy cover grew and patches merged throughout our study period, UTC tended to persist between years. Year to year, the percent of persistent UTC remained almost constant, suggesting that the amount of persistent UTC increased in proportion to overall UTC gain (Table 4; Fig. 3). These results highlight the importance of parks to urban UTC due to the highly persistent nature of UTC in these spaces.

Indeed, UTC goals-whether to increase, decrease, or stay the same-were not a primary aim of management in any of the parks that we studied. The ascension of UTC assessments and goal-setting in US urban forest management is a fairly recent phenomena, post 2006 (Grove et al. 2006; Hauer and Peterson 2016), facilitated by advancements in remote sensing analyses of current spatial patterns (O'Neil-Dunne et al. 2013) and the availability of free methods for UTC estimates (e.g., i-Tree Canopy was released in 2010, Nowak 2020). However, increasing or maximizing UTC may not align with other park management goals (Roman et al. 2017). For example, highly manicured lawn areas interspersed with trees and other vegetation can support pedestrian aesthetic preferences as well as recreational and

Page $15 / 25$ 
cultural landscape uses, like Cherry Blossom Festivals. Trees may also be removed to make way for other natural resource management or educational priorities, such as the tree losses we observed between 2000-2018 associated with specific restoration projects, a children's museum, and school construction (Figures 6-7). Indeed, the removal of non-native invasive trees is a fairly typical practice in modern ecological restoration activities (Dickie et al. 2014), although short-term canopy losses are expected to be followed by long-term gains in native tree cover and associated wildlife habitat (PPR 2013; Sher et al. 2018). The removal of trees to facilitate forest succession with native plants, or to make way for cultural and educational institutions, points to trade-offs in urban forestry goals related to UTC vs. broader ecological, social, and cultural functions of urban parks. In other words, increasing park UTC levels in and of itself does not necessarily produce the entire suite of ecosystem services attributed to urban trees, forests, and parks (Roy et al. 2012; Konijnendijk et al. 2013). Furthermore, unmaintained greenspaces may even produce disservices (Roman et al. 2021b). Accordingly, assessments of UTC should consider not only what levels are biophysically possible, but also what levels align with other landscape priorities and are socially preferable (Grove et al. 2006).

Mixed-methods approaches that integrate land change science with archival research and interviews are particularly well-suited for studies of UTC change because they not only quantify where and when change occurs, but also reveal the underlying drivers and impacts of these changes, as well as the controversies and tradeoffs underlying these drivers (e.g. highway construction). Our approach synthesized archival materials and the knowledge of park professionals to contextualize the UTC changes by highlighting the various benefits, drawbacks and tradeoffs for both human and ecological park uses. For example, discussions with park professionals at the Schuylkill Center revealed that some patches of tree cover loss could be linked directly to the creation of ponds, which provide their own unique educational and ecological benefits. Likewise, some forest restoration activities in Fairmount Park led to (likely temporary) UTC loss. These stories suggest that UTC loss in parks are sometimes explained by ecological goals. Examining archival materials helps humanize the spatiotemporal dynamics of UTC, uncovering underlying reasons for management choices while quantifying their impact on UTC change. In this way, the legacies of historical events, such as the decision to cut funding for park mowing, or to construct new buildings and parking lots, can be revealed - and quantified - decades later. UTC change is also highly variable and net change alone does not accurately reflect this dynamism. Our approach highlights how gains and losses vary across time and space in response to human and biophysical processes.

\section{Conclusion}

Our mixed-methods study illustrates the complexity of social drivers shaping UTC by quantifying UTC change in three Philadelphia parks and linking these changes to historical management practices. We found that differing management goals and practices led to UTC gains in each park. Contrary to expectations that more canopy is associated with intentional planting efforts and well-funded initiatives, we saw the greatest tree cover increases during a period of municipal budget cuts in the 1970s and 80s that led to mowing cessation in East and West Fairmount Park. During this period, unintentional forest emergence due to successional processes on unmaintained lands was a large driver of UTC gains. After 
an influx of new funding post-2000, we saw UTC losses linked to building construction and restoration efforts that included invasive species removal. Tree cover gains in the Schuylkill Center occurred as the landscape transitioned from agriculture to forest with the goal of supporting wildlife habitat and providing nature education. Losses in this park were largely linked to restoration activities and creation of pond and meadow habitat. Future research on UTC spatiotemporal dynamics should take advantage of the plethora of archival information in cities to explain the social dynamics that directly and indirectly impact UTC gains, losses, and persistence.

\section{Declarations}

Funding: This study was partially funded by the University Scholars Research Program at the University of Pennsylvania and a cooperative agreement between the USDA Forest Service and the Pennsylvania Horticultural Society, 16-JV-11242308-123.

Conflicts of interest: The authors declare no conflicts of interest.

Ethics approval: The authors declare no ethical concerns.

Consent to participate: All authors consented to participation in this study.

Consent for publication: All authors consent to the publication of the manuscript.

Availability of data and material: The shapefiles of tree canopy cover will be made available on the USDA Forest Service Data Archive. [*URL to come*]

Code availability: Not applicable.

\section{Author's contributions:}

Conceptualization: Sabine Nix, Lara Roman;

Methodology: Marc Healy, Sabine Nix, John Rogan, Lara Roman;

Formal analysis and investigation: Sabine Nix;

Writing (original draft preparation): Sabine Nix;

Writing (review and editing): Marc Healy, Hamil Pearsall, John Rogan, Lara Roman;

Funding acquisition: Sabine Nix, Lara Roman.

\section{References}

Ancestry (2020) Newspapers.com. https://www.newspapers.com. Accessed 1 April 2020. 
Armstrong R (2012) Green Space in the Gritty City: The Planning and Development of Philadelphia's Park System, 1854-1929. Lehigh University

Berland A (2012) Long-term urbanization effects on tree canopy cover along an urban-rural gradient. Urban Ecosyst 15(3):721-738. https://doi.org/10.1007/s11252-012-0224-9

Bonney M, He Y (2019) Attributing drivers to spatio-temporal changes in tree density across a suburbanizing landscape since 1944. Landscape Urban Plan 192:103652.

https://doi.org/10.1016/j.landurbplan.2019.103652

Brownlow A (2006) An archaeology of fear and environmental change in Philadelphia. Geoforum 37(2):227-245. https://doi.org/10.1016/j.geoforum.2005.02.009

Cherry Blossom Festival Tree Planting Ceremony (2000, March 16) The Philadelphia Inquirer, 22.

City of Philadelphia (2009) Greenworks Philadelphia Vision. Mayor's Office of Sustainability. https://www.phila.gov/media/20160419140515/2009-greenworks-vision.pdf. Accessed 20 February 2020

Collmore E (1990, August 30) The new view from the plateau. Philadelphia Inquirer, 1.

Commissioners of Fairmount Park (FPC) (1952) 85th Annual Report. 129 City Hall Philadelphia 7, Pennsylvania. 56pp.

Congalton RG, Mead RA (1983) A quantitative method to test for consistency and correctness in photointerpretation. Photogramm Eng Rem S 49(1):69-74.

Corr J (1990, August 16) Fountain of youths. Philadelphia Inquirer, 33, 36.

Dickie IA, Bennett BM, Burrows LE, Nuñez MA, Peltzer DA, Porté A, Richardson DM, Rejmánek M, Rundel PW, van Wilgen BW (2014) Conflicting values: Ecosystem services and invasive tree management. Biol Invasions 16(3):705-719. https://doi.org/10.1007/s10530-013-0609-6

Doroski DA, Felson AJ, Bradford MA, Ashton MP, Oldfield EE, Hallet RA, Kuebbing SE (2018) Factors driving natural regeneration beneath a planted urban forest. Urban For Urban Gree 29:238-247. https://doi.org/10.1016/j.ufug.2017.11.019

Dribben M (2006, May 7) Water Works. Philadelphia Inquirer, M04.

Dyer JM (2006) Revisiting the Deciduous Forests of Eastern North America. BioScience 56(4):341-352. https://doi.org/10.1641/0006-3568(2006)56[341:RTDFOE]2.0.CO;2

Environmental Systems Research Institute (ESRI) (2018) ArcGIS Release 10.6. Redlands, CA 
Escobedo FJ, Giannico V, Jim CY, Sanesi G, Lafortezza R (2019) Urban forests, ecosystem services, green infrastructure and nature-based solutions: Nexus or evolving metaphors? Urban For Urban Gree 37:3-12. https://doi.org/10.1016/j.ufug.2018.02.011

Expressway Completion in Sight (1958, July 13) Philadelphia Inquirer, 40.

Finkel K (1986, April 25) Fairmount Park: The neglected treasure. The Philadelphia Inquirer, 25.

Fish L (1998, January 16) Park's blossoms to multiply. The Philadelphia Inquirer, 24.

Fowler R (1970, October 29) 360-Acre Area Keeps Nature in City. The Philadelphia Inquirer, 15.

FPC (1958) 91st Annual Report. 129 City Hall Philadelphia 7, Pennsylvania. 55pp.

FPC (1959) 92nd Annual Report. 129 City Hall Philadelphia 7, Pennsylvania. 63pp.

FPC (1971-1972) One Hundredth and Fourth Annual Report. Memorial Hall. West Park, Philadelphia, Pennsylvania 19131. 60pp.

FPC (1973-74) One Hundredth and Sixth Annual Report. Memorial Hall. West Park, Philadelphia, Pennsylvania 19131. 62pp.

FPC (1974-1975) One Hundredth and Seventh Annual Report. Memorial Hall. West Park, Philadelphia, Pennsylvania 19131. 37pp.

FPC (1976-77) 109th Annual Report. Memorial Hall. West Park, Philadelphia, Pennsylvania 19131. 76pp.

FPC (1997-1998) My Fairmount Park. 1997-1998 Annual Report. 16pp.

FPC (July 1, 1969 - June 30, 1970) One Hundredth and Second Annual Report. Memorial Hall. Philadelphia, Pennsylvania 19131. 36pp.

FPC (July 1, 1991 - June 30, 1992) Annual Report of FPC. 41pp.

FPC (July 1986 - June 1987) 120th Year Report. Memorial Hall. West Park, Philadelphia, Pennsylvania 19131. 24pp.

FPC (June 1987-July 1988) 121st Annual Report.. Memorial Hall. West Park, Philadelphia, Pennsylvania 19131. $21 \mathrm{pp}$.

Gabriel N (2016) "No place for wilderness": Urban parks and the assembling of neoliberal urban environmental governance. Urban For Urban Gree 19:278-284.

https://doi.org/10.1016/j.ufug.2016.02.006

Goldenberg NA, Horwitz R (2000, February 18) Saving nature is no walk in the park. Philadelphia Daily News, 19. 
Grove JM, O’Neil-Dunne J, Pelletier K, Nowak D, Walton J (2006) A Report on New York City's Present and Possible Urban Tree Canopy. U.S. Department of Agriculture Forest Service Northeastern Research Station, South Burlington, Vermont.

Haas AJ (1967, May 21) Nature Center is Approved On 252 Acres in Roxborough. The Philadelphia Inquirer, 22.

Haase D, Haase A, Rink D (2014) Conceptualizing the nexus between urban shrinkage and ecosystem services. Landscape Urban Plan 132:159-169. https://doi.org/10.1016/j.landurbplan.2014.09.003

Hauer R, Peterson W (2016) Municipal Tree Care and Management in the United States: A 2014 Urban \& Community Forestry Census of Tree Activities (No. 16-1). College of Natural Resources, University of Wisconsin.

Hilbert DR, Koeser AK, Roman LA, Hamilton K, Landry SM, Hauer RJ, Campanella H, McLean D, Andreu M, Perez H (2019) Development practices and ordinances predict inter-city variation in Florida urban tree canopy coverage. Landscape Urban Plan 190:103603.

https://doi.org/10.1016/j.landurbplan.2019.103603

Hostetler AE, Rogan J, Martin D, DeLauer V, O’Neil-Dunne J (2013) Characterizing tree canopy loss using multi-source GIS data in Central Massachusetts, USA. Remote Sens Lett 4(12):1137-1146. https://doi.org/10.1080/2150704X.2013.852704

In city's parks, money doesn't grow on trees (1986, January 30) The Philadelphia Inquirer, 28.

In-depth maintenance study begins at Fairmount Park. City and Suburban News in Brief (1980, August 13) Philadelphia Inquirer, 18.

Jeon SB, Olofsson P, Woodcock CE (2014) Land use change in New England: A reversal of the forest transition. J Land Use Sci 9(1):105-130. https://doi.org/10.1080/1747423X.2012.754962

Joassart-Marcelli P (2010) Leveling the Playing Field? Urban Disparities in Funding for Local Parks and Recreation in the Los Angeles Region. Environ Plann A: Economy and Space 42(5):1174-1192. https://doi.org/10.1068/a42198

Johnson LR, Handel SN (2016) Restoration treatments in urban park forests drive long-term changes in vegetation trajectories. Ecol Appl 26(3):940-956. https://doi.org/10.1890/14-2063

Kaspar J, Kendal D, Sore R, Livesley S (2017) Random point sampling to detect gain and loss in tree canopy cover in response to urban densification. Urban For Urban Gree 24:26-34. http://dx.doi.org/10.1016/j.ufug.2017.03.013

Konijnendijk CC, Annerstedt M, Nielsen AB, Maruthaveeran S (2013) Benefits of urban parks: A systematic review. A report for IPFRA. Copenhagen \& ALNARP. www.ifpra.org 
Leary M (1981, April 2) Green asks for more cuts (of grass) for Fairmount Park. The Philadelphia Inquirer, 19.

Lewis JA, Zipperer WC, Ernstson H, Bernik B, Hazen R, Elmqvist T, Blum MJ (2017) Socioecological disparities in New Orleans following Hurricane Katrina. Ecosphere 8(9):e01922.

https://doi.org/10.1002/ecs2.1922

Locke D, Romolini M, Galvin M, O’Neil-Dunne J, Strauss E (2017) Tree Canopy Change in Coastal Los Angeles, 2009-2014. Cities Environ 10(2). https://digitalcommons.Imu.edu/cate/vol10/iss2/3

Maller C, Townsend M, St Leger L, Henderson-Wilson C, Pryor A, Prosser L, Moore M (2009) Healthy parks, healthy people: The health benefits of contact with nature in a park context. The George Wright Forum 26:51-83.

Maxwell Smith J (1953, June 11) That Expressway Route. The Voice of the People. Philadelphia Inquirer, 20.

McCormack GR, Rock M, Toohey AM, Hignell D (2010) Characteristics of urban parks associated with park use and physical activity: A review of qualitative research. Health Place 16(4):712-726. https://doi.org/doi:10.1016/j.healthplace.2010.03.003

Milroy E (2012) "Pro bono publico": Ecology, history, and the creation of Philadelphia's Fairmount Park system. In: Black BB, Chiarappa M (Eds.) Nature's entrepôt: Philadelphia's urban sphere and its environmental thresholds. University of Pittsburgh Press, Pittsburgh, PA, pp 35-55

Milroy E (2016) The Grid and the River: Philadelphia's Green Places, 1682-1876. Pennsylvania State University Press, University Park, PA

Morgan JL, Gergel SE (2013) Automated analysis of aerial photographs and potential for historic forest mapping. Can J of Forest Res 43(8):699-710. https://doi.org/dx.doi.org/10.1139/cjfr-2012-0492

Morgan JL, Gergel SE, Coops NC (2010) Aerial Photography: A Rapidly Evolving Tool for Ecological Management. BioScience 60(1):47-59. https://doi.org/10.1525/bio.2010.60.1.9

Nase M, Kirkpatrick A (2017) Historical Summary of Land Management \& Restoration Practice at the Schuylkill Center

Nguyen VD, Roman LA, Locke DH, Mincey SK, Sanders JR, Smith Fichman E, Duran-Mitchell M, Tobing SL (2017) Branching out to residential lands: Missions and strategies of five tree distribution programs in the U.S. Urban For Urban Gree 22:24-35. https://doi.org/10.1016/j.ufug.2017.01.007

Nielsen AB, Van Den Bosch M, Maruthaveeran S, van den Bosch CK (2014) Species richness in urban parks and its drivers: A review of empirical evidence. Urban Ecosyst 17(1):305-327.

https://doi.org/10.1007/s11252-013-0316-1

Page 21/25 
Non-Stop to Jersey, by Expressway (1959, November 24) Philadelphia Inquirer, 14.

Nowak DJ (2020) Understanding i-Tree: Summary of programs and methods. General Technical Report NRS-200. Madison, WI: U.S. Department of Agriculture, Forest Service, Northern Research Station. 100 pp. https://doi.org/10.2737/NRS-GTR-200

Nowak DJ, Greenfield EJ (2012) Tree and impervious cover change in U.S. cities. Urban For Urban Gree 11(1):21-30. https://doi.org/10.1016/j.ufug.2011.11.005

O'Neil-Dunne J (2011) A Report on the City of Philadelphia's Existing and Possible Tree Canopy. University of Vermont Spatial Analysis Laboratory. www.fs.fed.us/nrs/utc/reports/UTC_Report_Phila delphia.pdf

O'Neil-Dunne J (2012) A Report on the City of New York's Existing and Possible Tree Canopy. University of Vermont Spatial Analysis Laboratory. https://www.fs.fed.us/nrs/utc/reports/UTC_NYC_Report_2010.pdf

O’Neil-Dunne J (2019) Tree Canopy Assessment Philadelphia, PA. University of Vermont Spatial Analysis Laboratory

O'Neil-Dunne JPM, MacFaden SW, Royar AR, Pelletier KC (2013) An object-based system for LiDAR data fusion and feature extraction. Geocarto Int 28(3):227-242.

https://doi.org/10.1080/10106049.2012.689015

Ogden LA, Aoki C, Grove JM, Sonti NF, Hall W, Locke D, Pickett STA, Avins M, Lauter K, Lagrosa J (2019) Forest ethnography: An approach to study the environmental history and political ecology of urban forests. Urban Ecosyst 22(1):49-63. https://doi.org/10.1007/s11252-018-0744-z

Oldfield EE, Warren RJ, Felson AJ, Bradford MA (2013) Challenges and future directions in urban afforestation. J Appl Ecol 50(5):1169-1177. https://doi.org/10.1111/1365-2664.12124

Park Board Yields to State on Route Of Expressway (1953a, June 4) Philadelphia Inquirer, 1.

Penman J (1987, September 5) View Observed. Philadelphia Inquirer, 8.

Pennsylania Horticultural Society (PHS) (1973) Yearbook of the Pennsylvania Horticultural Society. Philadelphia Horticultural Society, Philadelphia, Pennsylvania.

https://archive.org/details/yearbookofpennsy1973penn/mode/2up

Philadelphia Parks and Recreation (PPR) (2013) Parkland Forest Management Framework. 120 pp. https://www.phila.gov/documents/parkland-forest-management-framework/

Pregitzer CC, Charlop-Powers S, McCabe C, Hiple A, Gunther B, Bradford MA (2019) Untapped Common Ground: The Care of Forested Natural Areas in American Cities. Natural Areas Conservancy. 46 pp. https://naturalareasnyc.org/content/national/nac_careofurbannature_lores-singles.pdf?1553522646 
Richardson JJ, Moskal LM (2014) Uncertainty in urban forest canopy assessment: Lessons from Seattle, WA, USA. Urban For Urban Gree 13(1):152-157. https://doi.org/10.1016/j.ufug.2013.07.003

Roman LA, Catton IJ, Greenfield EJ, Pearsall H, Eisenman TS, Henning JG (2021a) Linking Urban Tree Cover Change and Local History in a Post-Industrial City. Land 10(4):403.

https://doi.org/10.3390/land10040403

Roman LA, Conway TM, Eisenman TS, Koeser AK, Ordóñez Barona C, Locke DH, Jenerette DG, Östberg J, Vogt J (2021b) Beyond 'trees are good': Disservices, management costs, and tradeoffs in urban forestry. Ambio 50(3):615-630. https://doi.org/10.1007/s13280-020-01396-8

Roman LA, Fristensky JP, Eisenman TS, Greenfield EJ, Lundgren RE, Cerwinka CE, Hewitt DA, Welsh CC (2017) Growing Canopy on a College Campus: Understanding Urban Forest Change through Archival Records and Aerial Photography. Environ Manage 60(6):1042-1061. https://doi.org/10.1007/s00267017-0934-0

Roman LA, Pearsall H, Eisenman TS, Conway TM, Fahey RT, Landry S, Vogt J, van Doorn NS, Grove JM, Locke DH, Bardekjian AC, Battles JJ, Cadenasso ML, van den Bosch CCK, Avolio M, Berland A, Jenerette DG, Mincey SK, Pataki DE, Staudhammer C (2018) Human and biophysical legacies shape contemporary urban forests: A literature synthesis. Urban For Urban Gree 31:157-168.

https://doi.org/10.1016/j.ufug.2018.03.004

Rosan CD, Pearsall H (2017) Growing a sustainable city?: The question of urban agriculture. University of Toronto Press

Rosen F (1958, May 25) Expressway Set for Completion by Labor Day. Philadelphia Inquirer, 29.

Roy S, Byrne J, Pickering C (2012) A systematic quantitative review of urban tree benefits, costs, and assessment methods across cities in different climatic zones. Urban For Urban Gree 11(4):351-363. https://doi.org/10.1016/j.ufug.2012.06.006

Sher AA, El Waer H, González E, Anderson R, Henry AL, Biedron R, Yue P (2018) Native species recovery after reduction of an invasive tree by biological control with and without active removal. Ecol Eng 111:167-175. https://doi.org/10.1016/j.ecoleng.2017.11.018

Smith V (2007, March 16) Restoring some of city's flow. Philadelphia Inquirer, E06.

Taxpayers' Suit Urges Ban on Expressway (1953b, November 18) Philadelphia Inquirer, 41.

The Trust for Public Land (2017) 2017 City park facts. The Trust for Public Land. https://www.tpl.org/2017-city-park-facts

Turner-Skoff JB, Cavender N (2019) The benefits of trees for livable and sustainable communities. Plants, People, Planet 1(4):323-335. https://doi.org/10.1002/ppp3.39 
U.S. Census Bureau (2010) Population, Census, April 1, 2010. U.S. Census Bureau.

https://www.census.gov/quickfacts/fact/table/philadelphiacountypennsylvania/POP010210

Ucar Z, Bettinger P, Merry K, Siry J, Bowker JM, Akbulut R (2016) A comparison of two sampling approaches for assessing the urban forest canopy cover from aerial photography. Urban For Urban Gree 16:221-230. https://doi.org/10.1016/j.ufug.2016.03.001

Ung E (2000, November 5) Driving nature back to nature. The Philadelphia Inquirer, 25.

Walls M (2014) Private Funding of Public Parks: Assessing the Role of Philanthropy (p. 24). Resources for the Future. https://media.rff.org/documents/RFF-IB-14-01.pdf

Washington L (1987, August 3) Park Bike Paths On a Down Cycle. Philadelphia Daily News, 16.

Yearbook of the Pennsylvania Horticultural Society. Volume (1969-1973). Year 1973. 200 pp. https://archive.org/details/yearbookofpennsy1973penn

Zhou W, Huang G, Pickett ST, Cadenasso ML (2011) 90 years of forest cover change in an urbanizing watershed: Spatial and temporal dynamics. Landscape Ecol 26(5):645. https://doi.org/10.1007/s10980011-9589-z

Zipperer WC (2002) Species composition and structure of regenerated and remnant forest patches within an urban landscape. Urban Ecosyst 6(4):271-290.

https://doi.org/10.1023/B:UEC0.0000004827.12561.d4

\section{Figures}

\section{Figure 1}

Study area boundaries for West Fairmount Park (excluding the Philadelphia Zoo), East Fairmount Park and the Schuylkill Center within Philadelphia

\section{Figure 2}

Percent of a) West Fairmount Park, b) East Fairmount Park, and c) Schuylkill Center tree cover patches by size class $\left(\mathrm{m}^{2}\right)$ in 1959, 1980, 2000, and 2018

\section{Figure 3}


UTC change in Fairmount Park (left) and Schuylkill Center (right) shown overlaying 1959, 1980 and 2000 imagery (top to bottom)

\section{Figure 4}

Multi-decadal UTC gains and losses in ( $a$ and b) Fairmount Park and the Schuylkill Center (c and b), shown overlaying 1959 imagery

\section{Figure 5}

Tree cover gain between 1959 and 2000 in areas of mowing cessation including a) Chamounix Drive, b) Greenland Nursery, and c) North George's Hill, and planting d) near I-76

\section{Figure 6}

UTC loss between 2000 and 2018 in areas of restoration a) near Greenland Nursery and b) north of the Horticulture Center, and in areas of construction near c) the Please Touch Museum and d) the School of the Future, shown overlaying 2000 imagery

\section{Figure 7}

Areas of a) tree growth in the Pine Plantation and b) tree loss linked to daylighting, shown overlaying 1980, 2000 and 2018 imagery

\section{Supplementary Files}

This is a list of supplementary files associated with this preprint. Click to download.

- NixetalOnlineResource1.docx 